\title{
EXPLAINING THE GEOMETRY OF SIMPLE MOLECULES USING MOLECULAR ORBITAL ENERGY-LEVEL DIAGRAMS BUILT BY USING SYMMETRY PRINCIPLES
}

\author{
Sérgio P. Machado and Roberto B. Faria*
}

Departamento de Química Inorgânica, Instituto de Química, Universidade Federal do Rio de Janeiro, 21941-909 Rio de Janeiro - RJ, Brasil

Recebido em 27/08/2017; aceito em 08/01/2018; publicado na web em 08/02/2018

\begin{abstract}
The built of qualitative energy-level molecular diagrams for different geometries of simple molecules allow to explain the preferred geometry. The diagrams are built using simple symmetry principles and explain, on basis of the number of nonbonding electrons, for example, why the molecule of water is bent and not linear and ammonia is pyramidal and not planar. This simple energy principle does not need to consider the Valence Shell Electron-Pair Repulsion theory (VSEPR theory) neither hybrid orbitals to explain the geometry of simple molecules. This discussion is more appropriate to inorganic chemistry courses where symmetry is a common topic.
\end{abstract}

Keywords: symmetry; group theory; molecular orbitals; molecular geometry

\section{INTRODUCTION}

The geometries of molecules like $\mathrm{H}_{2} \mathrm{O}, \mathrm{NH}_{3}$ and $\mathrm{CH}_{4}$ are usually explained, at undergraduate level, in general and inorganic chemistry courses, using the Valence Shell Electron-Pair Repulsion theory (VSEPR theory) and hybrid orbitals. ${ }^{1-6}$ In the case of the VSEPR the starting point is the Lewis structure of each compound. It is considered that electrons groups around the central atom will be as far as possible, producing the observed molecular geometry (linear for two electrons groups, triangular for three electrons groups, tetrahedral for four electrons groups, and so on). In the case of the molecules indicated above, all of them have four electron groups but some of these have lone pairs resulting in the $\mathrm{H}_{2} \mathrm{O}$ bent, $\mathrm{NH}_{3}$ pyramidal, and $\mathrm{CH}_{4}$ tetrahedral geometry, as it is well known.

When using hybrid orbitals, the central atom in all these molecules is considered to use $\mathrm{sp}^{3}$ orbitals, which corresponds to the tetrahedral geometry. In this case some $\mathrm{sp}^{3}$ hybrid orbitals contain lone pair of electrons, resulting in the observed geometry for the cited molecules.

On the other hand, in the inorganic chemistry courses, when part of the time is dedicated to the application of symmetry to build the symmetry-adapted linear combinations of atomic orbitals, the stability of these molecules can be discussed more properly based on the molecular orbital energy-level diagrams for these molecules. Several inorganic chemistry textbooks present a very detailed molecular orbital energy-level diagrams for several simple molecules, for example, $\mathrm{BeH}_{2}, \mathrm{CO}_{2}$, and $\mathrm{H}_{2} \mathrm{O}$, justifying their geometries based on the occupancy of the molecular orbitals. However, as far we know, these textbooks do not present a discussion of what happen with the molecular energy if we consider a molecule with a different geometry. ${ }^{4-6}$ More specialized books on spectroscopy, ${ }^{7}$ present a discussion based on the change of the energy of molecular orbitals as the geometry of a molecule is gradually changed, for example, in the case of $\mathrm{AH}_{2}$ species, changing from linear to bent geometry. This kind of discussion is based on qualitative Walsh diagrams. ${ }^{8-14}$ These Walsh diagrams describe how the energy of each molecular orbital changes as the molecular geometry is modified between two possibilities as, for example, linear and bent geometries. These gradual modifications on the energy of the molecular orbitals, however, in some cases, are not easy to forecast, making difficult the discussion in class.

*e-mail: faria@iq.ufrj.br
Other works deal with the same subject we present in this article. Mulliken ${ }^{15}$ presents a discussion on $\mathrm{NH}_{3}$ which considers this molecule in the geometries pyramidal and plane trigonal. However, he concludes that the pyramidal geometry is the preferred because of the mixing between $\mathrm{s}$ and $\mathrm{p}_{\mathrm{z}}$ nitrogen in bonding molecular orbitals of the pyramidal geometry. Baird ${ }^{16}$ presents a discussion on the geometries of several $\mathrm{AX}_{\mathrm{n}}$ molecules which is based on Walsh diagrams for the highest occupied molecular orbitals. Miller and Ellison ${ }^{17}$ also present Walsh diagrams calculated by a computational chemistry software for a series of $\mathrm{AX}_{\mathrm{n}}$ molecules, allowing discussing their geometries.

In this work we present the use of qualitative molecular orbital energy-level diagrams built from simple group theory principles of symmetry. However, differently from the articles cited above, our approach is based on the different occupancy of nonbonding molecular orbitals for each geometry of the molecule considered. This allows explain the preferred geometry of simple molecules without requiring the building of complete Walsh diagram. Our approach is simpler and is based mainly in the number of electrons on nonbonding molecular orbitals.

Symmetry is a common subject in inorganic chemistry courses (most commonly third or fourth semester or even later) and undergraduate students are very familiar with it. In this way, we have used the approach described below in the undergraduate inorganic chemistry course. We observed that the comparison of the energy-level molecular diagrams for different geometries of an specific molecule is a very significant application of symmetry and molecular orbital theory which gives a very strong support to more deep discussions of chemical bond based on molecular orbitals. The inclusion of this subject allowed show for the students a simple and direct application of symmetry and group theory on the very basic topic of molecular geometry together with the presentation of fundamental aspects of symmetry. This was a very significant improvement because we start to show an application of these principles earlier than before. Students, usually, are very anxious about where they will apply this knowledge, which is abstract, mathematical and spatial reasoning, being difficult for most part of the class. Before we have included this subject, the students need wait for the first application of symmetry until the discussing the electronic spectroscopy of transition metal complexes. As a consequence, we observed a very clear improvement in the number 
of the students which obtained higher grades in the questions related with the basic principles of symmetry and group theory. We did not apply a tool to measure this improvement but we estimated that 70 to $80 \%$ of the class have increased their comprehension level.

The starting point of this approach is the identification of the irreducible representation of the atomic orbitals. After that, the energy level diagram of the molecular orbitals is built, combining the atomic orbitals of the same irreducible representation. Then, the molecular orbitals are filled with the electrons using the aufbau principle. Comparison of the number of electrons which occupy bonding, antibonding, and nonbonding orbitals, at each different geometry of the same molecule, allows explain its preferred molecular geometry. In the following we consider that the reader knows the basic principles of Group Theory applied to chemistry including symmetry operations and the use of the Character Tables. ${ }^{4-6,18-22}$

\section{THE WATER MOLECULE}

This molecule has only two possible geometries indicated in Figure 1: linear $\left(\mathrm{D}_{\infty \mathrm{ch}}\right)$ and bent $\left(\mathrm{C}_{2 \mathrm{v}}\right)$. The convention for the coordinate system and axis is the same used by Orchin and Jaffé, ${ }^{7}$ in which the $\mathrm{x}$ axis is perpendicular to the plane of the molecule.

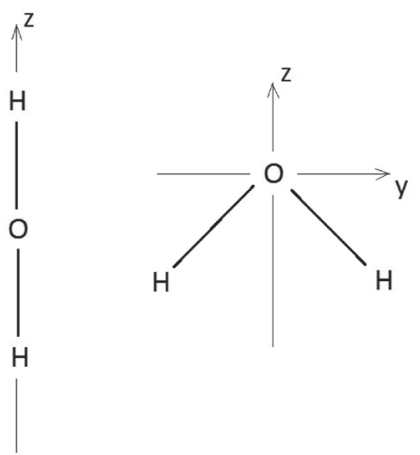

Figure 1. The two possible geometries for the water molecule: linear $\left(D_{\infty \mathrm{ch}}\right)$ and bent $\left(C_{2 v}\right)$

In the case of the bent geometry the molecule belongs to the point group $\mathrm{C}_{2 \mathrm{v}}$ and its Character Table allows to identify the irreducible representation of each oxygen (the central atom) atomic orbital based on the last column indications (see Table 1). The $2 \mathrm{~s}$ orbital has a spherical symmetry and belongs to the totally symmetric irreducible representation which is always the first to appear in any Character Table, in this case $A_{1}$. The orbitals $2 p_{x}, 2 p_{y}$, and $2 p_{z}$ belongs to $B_{1}$, $B_{2}$, and $A_{1}$, respectively. How these assignments are made, is shown below for the symmetry operations of the group $\mathrm{C}_{2 v}$, as an example. For other point groups this can be found in many textbooks which show how to find the irreducible representation of the atomic orbitals in a molecule..$^{4,58-11}$

In the case of the $\hat{C}_{2}, \hat{\sigma}_{\mathrm{v}}{ }^{(\mathrm{xz})}$, and $\hat{\sigma}_{\mathrm{v}}^{\prime}{ }^{(\mathrm{yz})}$ symmetry operators the orbitals $2 p_{x}, 2 p_{y}$, and $2 p_{z}$ transform as shown in Figures 2, 3, and 4 , respectively.

To identify the irreducible representation for each orbital the result of the application of the symmetry operator is taken as equal to 1 if the orbital does not change and the result is -1 if the orbital changes its signal. In this way, Table 1 shows the results and the attribution of an irreducible representation for each oxygen atomic orbital $2 \mathrm{p}_{\mathrm{x}}, 2 \mathrm{p}_{\mathrm{y}}$, and $2 \mathrm{p}_{\mathrm{z}}$.

For the 1s atomic orbitals on each hydrogen (peripheral atoms), indicated by s ${ }^{\mathrm{H1}}$ and $\mathrm{s}^{\mathrm{H} 2}$, they cannot be considered separately. As the $\hat{C}_{2}$ symmetry operator exchange both $1 \mathrm{~s}$ atomic orbitals, they must be considered together using a two-dimensional matrix. In the case
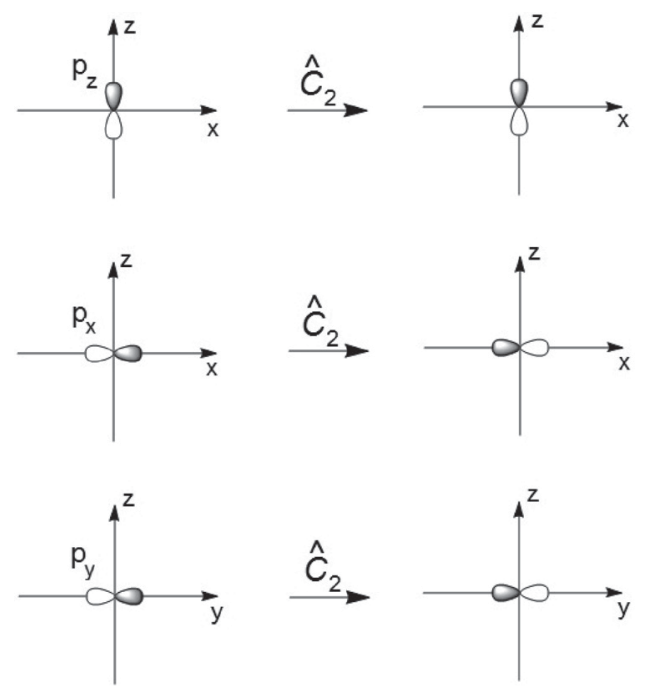

Figure 2. Results for the application of the $\hat{C}_{2}$ operator (on the $z$ axis), of the $\left(C_{2 v}\right)$ point group, over the $2 p_{x}, 2 p_{y}$ and $2 p_{z}$ oxygen orbitals of the water molecule
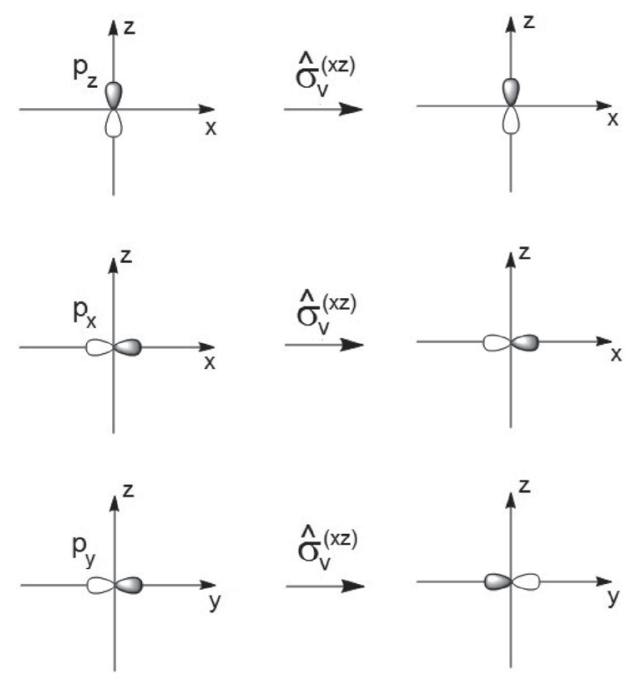

Figure 3. Results for the application of the operator $\hat{\sigma}_{v}{ }^{(x z)}$, of the $\left(C_{2 v}\right)$ point group, over the $2 p_{x}, 2 p_{y}$, and $2 p_{z}$ oxygen orbitals of the water molecule
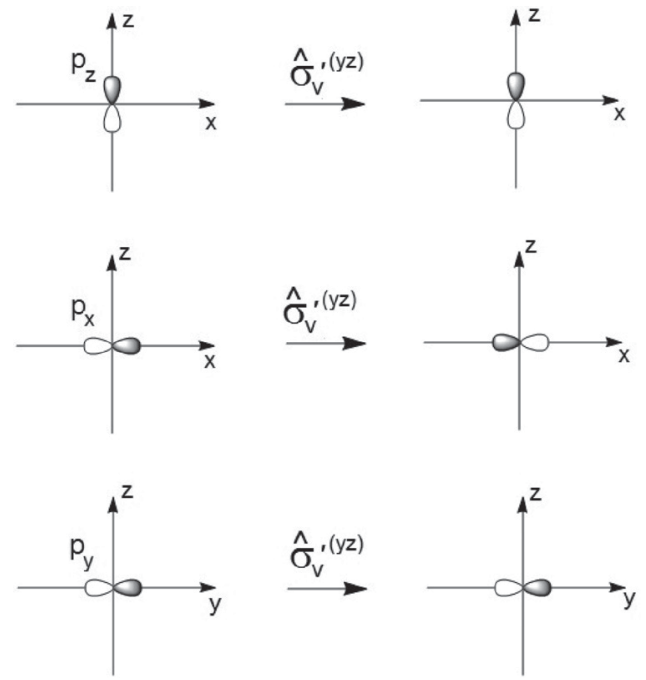

Figure 4. Results for the application of the operator $\hat{\sigma}_{v}^{\prime}{ }_{v}^{(y z)}$, of the $\left(C_{2 v}\right)$ point group, over the $2 p_{x}, 2 p_{y}$, and $2 p_{z}$ oxygen orbitals of the water molecule 
Table 1. Applying the $\mathrm{C}_{2 \mathrm{v}}$ symmetry operations to oxygen $2 \mathrm{p}_{\mathrm{x}}, 2 \mathrm{p}_{\mathrm{y}}$, and $2 \mathrm{p}_{\mathrm{z}}$ atomic orbitals in the water molecule

\begin{tabular}{llrrrr}
\hline $\mathrm{C}_{2 \mathrm{v}}$ & $\mathrm{E}$ & $\mathrm{C}_{2}$ & $\sigma_{\mathrm{v}}^{(\mathrm{xz})}$ & \multicolumn{3}{c}{$\sigma_{\mathrm{v}}^{(\mathrm{yz})}$} \\
\hline $\mathrm{A}_{1}$ & 1 & 1 & 1 & 1 & $z$ \\
$\mathrm{~A}_{2}$ & 1 & 1 & -1 & -1 & \\
$\mathrm{~B}_{1}$ & 1 & -1 & 1 & -1 & $x$ \\
$\mathrm{~B}_{2}$ & 1 & -1 & -1 & 1 & $y$ \\
\hline $2 \mathrm{p}_{\mathrm{x}}$ & 1 & -1 & 1 & -1 & $\mathrm{~B}_{1}$ \\
$2 \mathrm{p}_{\mathrm{y}}$ & 1 & -1 & -1 & 1 & $\mathrm{~B}_{2}$ \\
$2 \mathrm{p}_{\mathrm{z}}$ & 1 & 1 & 1 & 1 & $\mathrm{~A}_{1}$ \\
\hline
\end{tabular}

of the identity symmetry operation, the matrix representation of this operation can be indicated as

$$
\begin{aligned}
& \begin{array}{llll}
\text { sH1 } & \mathrm{sH} 2 & \mathrm{sH} 1 & \mathrm{sH} 2
\end{array} \\
& \begin{array}{llllll}
\mathrm{sH} 1 & 1 & 0 & -\hat{E} \longrightarrow \mathrm{sH} 1 & 1 & 0 \\
\mathrm{sH} 2 & 0 & 1
\end{array}
\end{aligned}
$$

This notation can be simplified considering that the first column and first line of the matrices refer to the $\mathrm{sH} 1$ atomic orbital and the second column and second line refer to the $\mathrm{sH} 2$ atomic orbital. In addition, the character or the trace of the matrix $(\chi$, the sum of the main diagonal elements) is also indicated.

$\hat{E}\left(\begin{array}{ll}1 & 0 \\ 0 & 1\end{array}\right)=\left(\begin{array}{ll}1 & 0 \\ 0 & 1\end{array}\right) ; \quad \chi(\hat{E})=\operatorname{tr}\left(\begin{array}{ll}1 & 0 \\ 0 & 1\end{array}\right)=2$

$\hat{C}_{2}\left(\begin{array}{ll}1 & 0 \\ 0 & 1\end{array}\right)=\left(\begin{array}{ll}0 & 1 \\ 1 & 0\end{array}\right) ; \quad \chi\left(\hat{C}_{2}\right)=\operatorname{tr}\left(\begin{array}{ll}0 & 1 \\ 1 & 0\end{array}\right)=0$

$\hat{\sigma}_{\mathrm{v}}{ }^{(\mathrm{xz})}\left(\begin{array}{ll}1 & 0 \\ 0 & 1\end{array}\right)=\left(\begin{array}{ll}0 & 1 \\ 1 & 0\end{array}\right) ; \quad \chi\left(\hat{\sigma}_{\mathrm{v}}{ }^{(\mathrm{xz})}\right)=\operatorname{tr}\left(\begin{array}{ll}0 & 1 \\ 1 & 0\end{array}\right)=0$

$\hat{\sigma}_{\mathrm{v}}^{\prime(\mathrm{yz})}\left(\begin{array}{ll}1 & 0 \\ 0 & 1\end{array}\right)=\left(\begin{array}{ll}1 & 0 \\ 0 & 1\end{array}\right) ; \quad \chi\left(\hat{\sigma}^{\prime}{ }_{\mathrm{v}}^{(\mathrm{yz})}\right)=\operatorname{tr}\left(\begin{array}{ll}1 & 0 \\ 0 & 1\end{array}\right)=2$

These results show that $1 \mathrm{~s}$ atomic orbitals of the hydrogens produce a reducible representation which can be shown to be formed by the sum $A_{1}+B_{2}$ (see Table 2 ).

Table 2. Applying the $\mathrm{C}_{2 v}$ symmetry operations to hydrogen 1s atomic orbitals in the water molecule

\begin{tabular}{cccccc}
\hline $\mathrm{C}_{2 \mathrm{v}}$ & $\mathrm{E}$ & $\mathrm{C}_{2}$ & $\sigma_{\mathrm{v}}^{(\mathrm{xz})}$ & $\sigma_{\mathrm{v}}^{(\mathrm{yz})}$ & \\
\hline $\mathrm{A}_{1}$ & 1 & 1 & 1 & 1 & $z$ \\
$\mathrm{~A}_{2}$ & 1 & 1 & -1 & -1 & \\
$\mathrm{~B}_{1}$ & 1 & -1 & 1 & -1 & $x$ \\
$\mathrm{~B}_{2}$ & 1 & -1 & -1 & 1 & $y$ \\
\hline$\left(\mathrm{s}^{\mathrm{H} 1}, \mathrm{~s}^{\mathrm{H} 2}\right)$ & 2 & 0 & 0 & 2 & $\mathrm{~A}_{1}+\mathrm{B}_{2}$ \\
\hline
\end{tabular}

With this information we can set up the energy level diagram for the molecular orbitals of water (Figure 5), considering that only atomic orbitals of the same symmetry species can combine. The symmetry labels are written in lower case when indicating atomic and molecular orbitals. Note also that the $2 \mathrm{p}_{\mathrm{x}}$ oxygen atomic orbital does not have any hydrogen orbitals to combine and because of this it stays as a $b_{1}$ nonbonding molecular orbital which has the same energy level of the $2 p_{x}$ atomic orbital.

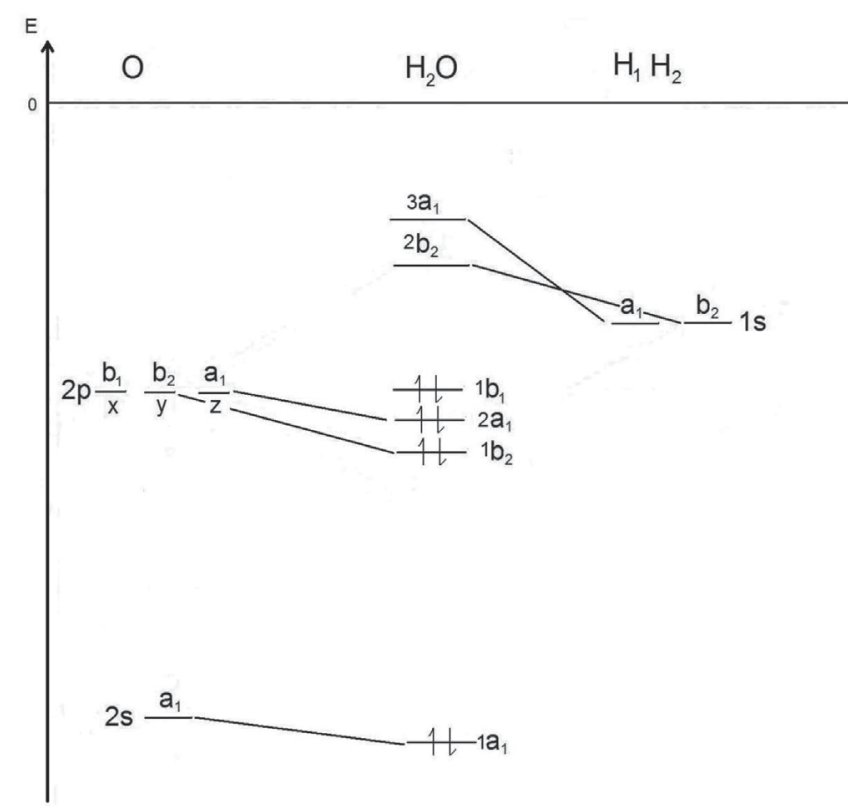

Figure 5. Qualitative molecular orbital energy-level diagram for water in the bent geometry $\left(C_{2 v}\right)$

Now, let us consider the possibility that the water molecule is linear. In this case the molecule will belongs to the point group $\mathrm{D}_{\infty \mathrm{h}}$ (Figure 1). Using the information on the last column of the Character Table (Table 3) we can assign the oxygen atomic orbitals to the following irreducible representations: $2 \mathrm{~s}\left(\Sigma_{\mathrm{g}}{ }^{+}\right.$, the totally symmetric representation), $2 \mathrm{p}_{\mathrm{z}}\left(\Sigma_{\mathrm{u}}^{+}\right)$, and $2 \mathrm{p}_{\mathrm{x}}$ and $2 \mathrm{p}_{\mathrm{y}}$ together $\left(\Pi_{\mathrm{u}}\right)$.

In the case of the hydrogen $1 \mathrm{~s}$ atomic orbitals, any $\hat{C}_{2}$ perpendicular to the principal axis $(\mathrm{z})$ will exchange the hydrogens 1s orbitals in the atoms $\mathrm{H} 1$ and $\mathrm{H} 2$ and because of this they must be worked together using two dimensional matrixes, as shown below.

$\hat{E}\left(\begin{array}{ll}1 & 0 \\ 0 & 1\end{array}\right)=\left(\begin{array}{ll}1 & 0 \\ 0 & 1\end{array}\right) ; \quad \chi(\hat{E})=\operatorname{tr}\left(\begin{array}{ll}1 & 0 \\ 0 & 1\end{array}\right)=2$

$\hat{C}_{\infty}^{\phi}\left(\begin{array}{ll}1 & 0 \\ 0 & 1\end{array}\right)=\left(\begin{array}{ll}1 & 0 \\ 0 & 1\end{array}\right) ; \quad \chi\left(\hat{C}_{\infty}^{\phi}\right)=\operatorname{tr}\left(\begin{array}{ll}1 & 0 \\ 0 & 1\end{array}\right)=2$

$\infty \hat{\sigma}_{\mathrm{v}}\left(\begin{array}{ll}1 & 0 \\ 0 & 1\end{array}\right)=\left(\begin{array}{ll}1 & 0 \\ 0 & 1\end{array}\right) ; \quad \chi\left(\infty \hat{\sigma}_{\mathrm{v}}\right)=\operatorname{tr}\left(\begin{array}{ll}1 & 0 \\ 0 & 1\end{array}\right)=2$

$\hat{i}\left(\begin{array}{ll}1 & 0 \\ 0 & 1\end{array}\right)=\left(\begin{array}{ll}0 & 1 \\ 1 & 0\end{array}\right) ; \quad \chi(\hat{i})=\operatorname{tr}\left(\begin{array}{ll}0 & 1 \\ 1 & 0\end{array}\right)=0$

$\hat{S}_{\infty}{ }^{\phi}\left(\begin{array}{ll}1 & 0 \\ 0 & 1\end{array}\right)=\left(\begin{array}{ll}0 & 1 \\ 1 & 0\end{array}\right) ; \quad \chi\left(\hat{S}_{\infty}^{\phi}\right)=\operatorname{tr}\left(\begin{array}{ll}0 & 1 \\ 1 & 0\end{array}\right)=0$

$\infty \hat{C}_{2}\left(\begin{array}{ll}1 & 0 \\ 0 & 1\end{array}\right)=\left(\begin{array}{ll}0 & 1 \\ 1 & 0\end{array}\right) ; \quad \chi\left(\infty \hat{C}_{2}\right)=\operatorname{tr}\left(\begin{array}{ll}0 & 1 \\ 1 & 0\end{array}\right)=0$

These results show that $1 \mathrm{~s}$ hydrogen orbitals $\left(\mathrm{s}^{\mathrm{H} 1}, \mathrm{~s}^{\mathrm{H} 2}\right)$ produce a reducible representation which can be shown that is formed by $\Sigma_{\mathrm{g}}^{+}+\Sigma_{\mathrm{u}}{ }^{+}$(see Table 3$)$.

Using these results we can build the molecular orbital energylevel diagram for the water molecule in the linear geometry $\left(D_{\infty \mathrm{h}}\right)$, as is shown in Figure 6. Note that now the $2 p_{x}$ and $2 p_{y}$ oxygen atomic orbitals do not have any hydrogen orbitals with the same irreducible representation to combine and because of this they stay as a $\pi_{\mathrm{u}}$ nonbonding molecular orbital which has the same energy level of the $2 p_{x}$ and $2 p_{y}$ atomic orbitals. 
Table 3. Applying the $\mathrm{D}_{\infty \mathrm{h}}$ symmetry operations to the hydrogen $1 \mathrm{~s}$ atomic orbitals of the linear water molecule

\begin{tabular}{|c|c|c|c|c|c|c|c|c|c|}
\hline$D_{\propto \mathrm{h}}$ & $\mathrm{E}$ & $2 \mathrm{C}_{\infty}^{\varphi}$ & $\ldots$ & $\infty \sigma_{\mathrm{v}}$ & $\mathrm{i}$ & $2 \mathrm{~S}_{\infty}{ }^{\varphi}$ & $\ldots$ & $\infty \mathrm{C}_{2}$ & \\
\hline$\Sigma_{\mathrm{g}}^{+}$ & 1 & 1 & $\ldots$ & 1 & 1 & 1 & $\ldots$ & 1 & \\
\hline$\Sigma_{\mathrm{g}}^{-}$ & 1 & 1 & $\ldots$ & -1 & 1 & 1 & $\ldots$ & -1 & \\
\hline$\Pi_{g}$ & 2 & $2 \cos \varphi$ & $\ldots$ & 0 & 2 & $-2 \cos \varphi$ & $\ldots$ & 0 & \\
\hline$\Delta_{g}$ & 2 & $2 \cos 2 \varphi$ & $\ldots$ & 0 & 2 & $2 \cos 2 \varphi$ & $\ldots$ & 0 & \\
\hline$\Sigma_{\mathrm{u}}^{+}$ & 1 & 1 & $\ldots$ & 1 & -1 & -1 & $\ldots$ & -1 & $z$ \\
\hline$\Sigma_{\mathrm{u}}^{-}$ & 1 & 1 & $\ldots$ & -1 & -1 & -1 & $\ldots$ & 1 & \\
\hline$\Pi_{\mathrm{u}}$ & 2 & $2 \cos \varphi$ & $\ldots$ & 0 & -2 & $2 \cos \varphi$ & $\ldots$ & 0 & $(x, y)$ \\
\hline$\Delta_{\mathrm{u}}$ & 2 & $2 \cos 2 \varphi$ & $\ldots$ & 0 & -2 & $-2 \cos 2 \varphi$ & $\ldots$ & 0 & \\
\hline$\left(\mathrm{s}^{\mathrm{H} 1}, \mathrm{~s}^{\mathrm{H} 2}\right)$ & 2 & 2 & & 2 & 0 & 0 & & 0 & $\Sigma_{\mathrm{g}}{ }^{+}+\Sigma_{\mathrm{u}}{ }^{+}$ \\
\hline
\end{tabular}

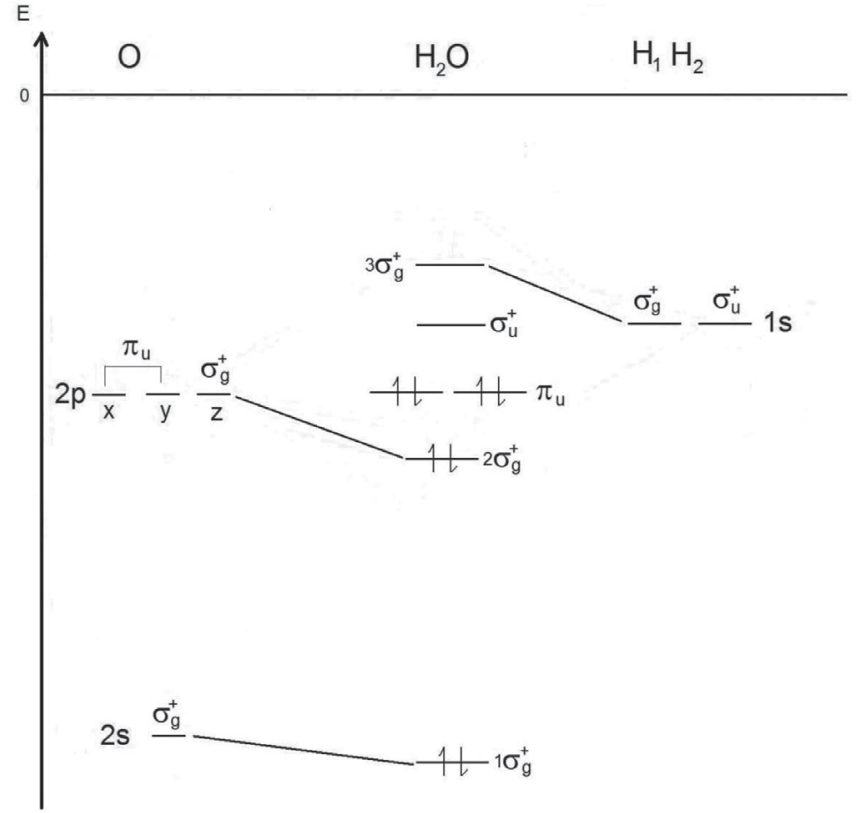

Figure 6. Qualitative molecular orbital energy-level diagram for water in the linear geometry $\left(D_{\infty \circ h}\right)$

Comparison between Figures 5 and 6 shows that in the linear geometry the water molecule has four electrons in two $\pi_{\mathrm{u}}$ nonbonding molecular orbitals, but in the bent geometry it has only two electrons in the $b_{1}$ nonbonding molecular orbital, being more stable in this geometry because it has more electrons in lower energy levels.

Clearly the reason for the bent geometry of the water molecule is that one of the $\pi_{\mathrm{u}}$ nonbonding molecular orbitals in the linear geometry becomes a bonding molecular orbital in the bent geometry, decreasing the energy of the molecule. The other $\pi_{\mathrm{u}}$ nonbonding molecular orbital stays as a $\mathrm{b}_{1}$ nonbonding.

Some authors ${ }^{8,16,17}$ discuss in more detail the transformation of one set of orbitals in the other, as the geometry is changed from linear to bent, using the very well-known Walsh diagrams. This is a more detailed discussion which is necessary to explain the geometry of species with a lower number of electrons, like $\mathrm{BeH}_{2}, \mathrm{CH}_{2}, \mathrm{NH}_{2}$, and $\mathrm{BH}_{2}{ }^{+}$, which are linear. In the case of water, it is necessary consider only the number of nonbonding electrons in both geometry.

It is worth to say that the conclusion that water is bent was obtained without consider the repulsion between the electrons pairs in the VSEPR theory or by the use of $\mathrm{sp}^{3}$ hybrid orbitals. In addition, the presence of three low energy peaks in the photoelectron spectrum of water is in a better agreement with the molecular orbital energy-level presented in Figure 5 than the presence of two $\mathrm{sp}^{3}$ nonbonding equivalent orbitals. ${ }^{23}$

\section{THE AMMONIA MOLECULE}

The same approach used with the water molecule can be applied to explain the most stable geometry of other simple molecules. Let us now consider the $\mathrm{NH}_{3}$ molecule in two different geometries: pyramidal $\left(\mathrm{C}_{3 \mathrm{v}}\right)$ and planar $\left(\mathrm{D}_{3 \mathrm{~h}}\right)$ (Figure 7$)$. Application of the same symmetry principles produces the results shown in Table 4 .

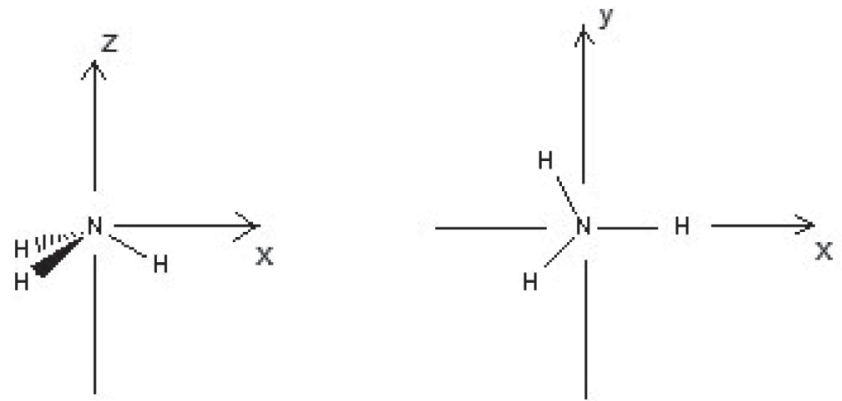

Figure 7. The two possible geometries for the ammonia molecule: pyramidal $\left(C_{3 v}\right)$ and planar $\left(D_{3 h}\right)$

Table 4. Applying the $\mathrm{C}_{3 \mathrm{v}}$ symmetry operations to the atomic orbitals of the $\mathrm{NH}_{3}$ molecule

\begin{tabular}{ccccc}
\hline $\mathrm{C}_{3 \mathrm{v}}$ & $\mathrm{E}$ & $2 \mathrm{C}_{3}$ & $3 \sigma_{\mathrm{v}}$ & \\
\hline $\mathrm{A}_{1}$ & 1 & 1 & 1 & $z$ \\
$\mathrm{~A}_{2}$ & 1 & 1 & -1 & \\
$\mathrm{E}$ & 2 & -1 & 0 & $(x, y)$ \\
\hline$\left(\mathrm{s}^{\mathrm{H} 1}, \mathrm{~s}^{\mathrm{H} 2}, \mathrm{~s}^{\mathrm{H} 3}\right)$ & 3 & 0 & 1 & $\mathrm{~A}_{1}+\mathrm{E}$ \\
\hline
\end{tabular}

From these results we can say that both nitrogen $2 \mathrm{~s}$ and $2 \mathrm{p}_{\mathrm{z}}$ atomic orbitals belong to the irreducible representation $\mathrm{A}_{1}$ and the orbitals $2 p_{x}$ and $2 p_{y}$ belongs to the irreducible representation $E$. The three hydrogen $1 \mathrm{~s}$ orbitals produce a reducible representation, which decomposes to $\mathrm{A}_{1}+\mathrm{E}$. With this information the qualitative molecular orbital energy-level diagram for $\mathrm{NH}_{3}$ can be assembled as shown in Figure 8, as it is presented in many textbooks, without any nonbonding molecular orbital.

Let us now consider the $\mathrm{NH}_{3}$ in the planar geometry $\left(\mathrm{D}_{3 \mathrm{~h}}\right)$. Application of the principles of symmetry produces the results shown in Table 5, which indicates that the nitrogen 2 s atomic orbital belongs to the irreducible representation $\mathrm{A}_{1}{ }^{\prime}$ (totally symmetric), 


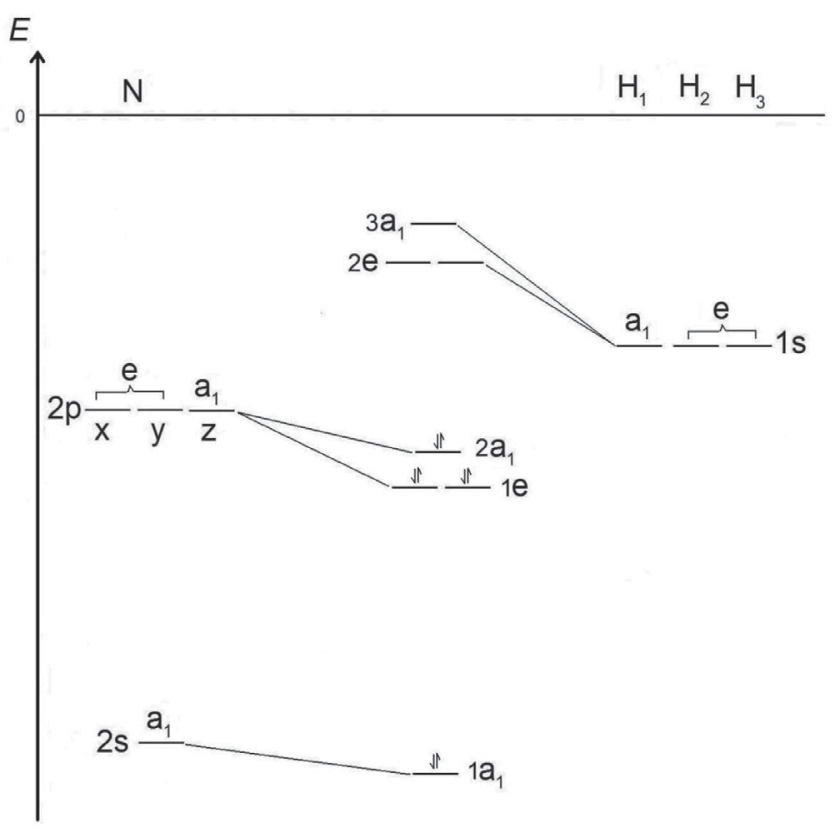

Figure 8. Qualitative molecular orbital energy-level diagram for $\mathrm{NH}_{3}$ in the pyramidal geometry $\left(C_{3 v}\right)$

Table 5. Applying the $\mathrm{D}_{3 \mathrm{~h}}$ symmetry operations to the atomic orbitals of the planar $\mathrm{NH}_{3}$ molecule

\begin{tabular}{ccrrrrrr}
\hline $\mathrm{D}_{3 \mathrm{~h}}$ & $\mathrm{E}$ & $2 \mathrm{C}_{3}$ & $3 \mathrm{C}_{2}$ & $\sigma_{\mathrm{h}}$ & $2 \mathrm{~S}_{3}$ & $3 \sigma_{\mathrm{v}}$ & \\
\hline $\mathrm{A}_{1}{ }^{\prime}$ & 1 & 1 & 1 & 1 & 1 & 1 & \\
$\mathrm{~A}_{2}{ }^{\prime}$ & 1 & 1 & -1 & 1 & 1 & -1 & \\
$\mathrm{E}^{\prime}$ & 2 & -1 & 0 & 2 & -1 & 0 & $(x, y)$ \\
$\mathrm{A}_{1}{ }^{\prime \prime}$ & 1 & 1 & 1 & -1 & -1 & -1 & \\
$\mathrm{~A}_{2}{ }^{\prime \prime}$ & 1 & 1 & -1 & -1 & -1 & 1 & $z$ \\
$\mathrm{E}^{\prime \prime}$ & 2 & -1 & 0 & -2 & 1 & 0 & \\
\hline$\left(\mathrm{s}^{\mathrm{H} 1}, \mathrm{~s}^{\mathrm{H} 2}, \mathrm{~s}^{\mathrm{H}}\right)$ & 3 & 0 & 1 & 3 & 0 & 1 & $\mathrm{~A}_{1}{ }^{\prime}+\mathrm{E}^{\prime}$ \\
\hline
\end{tabular}

the $2 \mathrm{p}_{\mathrm{z}}$ belongs to $\mathrm{A}_{2}{ }^{\prime \prime}$, and the orbitals $2 \mathrm{p}_{\mathrm{x}}$ and $2 \mathrm{p}_{\mathrm{y}}$ belongs to a twodimensional irreducible representation $\mathrm{E}^{\prime}$.

The three hydrogen $1 \mathrm{~s}$ orbitals produce a reducible representation which is formed by $A_{1}{ }^{\prime}+E^{\prime}$. Using this information the molecular orbital energy-level diagram for $\mathrm{NH}_{3}$ in the planar geometry $\left(\mathrm{D}_{3 \mathrm{~h}}\right)$ can be built, as shown in Figure 9, which presents one electron pair in the $\mathrm{a}_{2}{ }^{\prime \prime}$ nonbonding molecular orbital.

Comparison between Figures 8 and 9 shows that $\mathrm{NH}_{3}$ in the planar geometry has two electrons in the $\mathrm{a}_{2}{ }^{\prime \prime}$ nonbonding molecular orbitals, but in the pyramidal geometry it does not have electrons in nonbonding orbitals, being more stable in this geometry because it has more electrons in lower energy levels. Again the reason for the pyramidal geometry of the $\mathrm{NH}_{3}$ molecule is the lower energy of the valence electrons in this geometry compared with the planar geometry, independent from the lower repulsion between the electrons pairs in the VSEPR theory or by the use of $\mathrm{sp}^{3}$ hybrid orbitals.

\section{THE METHANE MOLECULE}

We can now consider the tetrahedral and planar geometry of methane, which belongs to the point groups $\mathrm{T}_{\mathrm{d}}$ and $\mathrm{D}_{4 \mathrm{~h}}$, respectively (Figure 10). Tables 6 and 7 and Figures 11 and 12 present the results for the application of symmetry concepts and the molecular orbital energy-level diagrams for both cases.

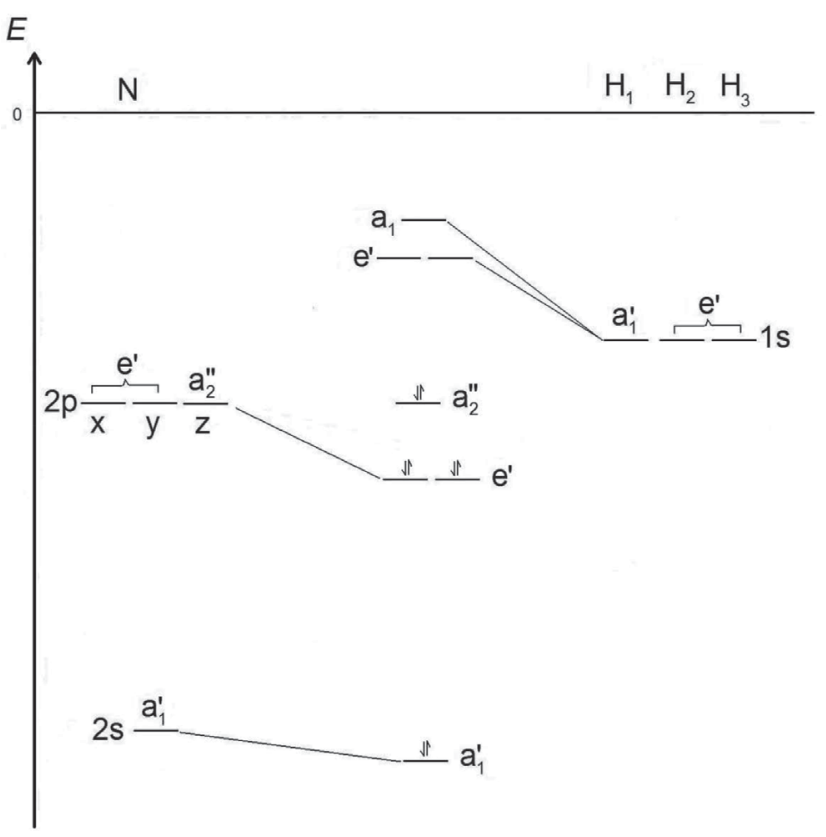

Figure 9. Qualitative molecular orbital energy-level diagram for $\mathrm{NH}_{3}$ in the planar geometry $\left(D_{3 h}\right)$

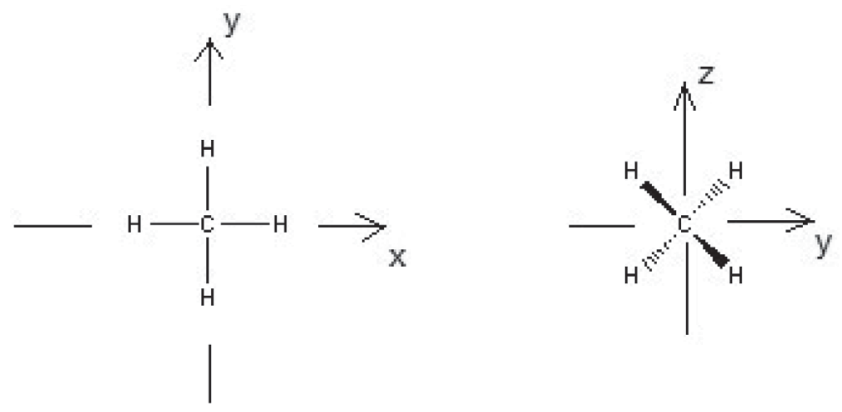

Figure 10. The two possible geometries for the methane molecule: square planar $\left(D_{4 h}\right)$ and tetrahedral $\left(T_{d}\right)$

Table 6. Applying the $T_{d}$ symmetry operations to the atomic orbitals of the tetrahedral $\mathrm{CH}_{4}$ molecule

\begin{tabular}{ccrrrrr}
\hline $\mathrm{T}_{\mathrm{d}}$ & $\mathrm{E}$ & $8 \mathrm{C}_{3}$ & $3 \mathrm{C}_{2}$ & $6 \mathrm{~S}_{4}$ & $6 \sigma_{\mathrm{d}}$ & \\
\hline $\mathrm{A}_{1}$ & 1 & 1 & 1 & 1 & 1 & \\
$\mathrm{~A}_{2}$ & 1 & 1 & 1 & -1 & -1 & \\
$\mathrm{E}$ & 2 & -1 & 2 & 0 & 0 & \\
$\mathrm{~T}_{1}$ & 3 & 0 & -1 & 1 & -1 & \\
$\mathrm{~T}_{2}$ & 3 & 0 & -1 & -1 & 1 & $(x, y, z)$ \\
\hline$\left(\mathrm{s}^{\mathrm{H1}}, \mathrm{s}^{\mathrm{H} 2}, \mathrm{~s}^{\mathrm{H3}}, \mathrm{s}^{\mathrm{H4}}\right)$ & 4 & 1 & 0 & 0 & 2 & $\mathrm{~A}_{1}+\mathrm{T}_{2}$ \\
\hline
\end{tabular}

As can be seen from Figures 11 and 12 the methane in the planar geometry $\left(\mathrm{D}_{4 \mathrm{~h}}\right)$ has one pair of electrons in the nonbonding $\mathrm{a}_{2 u}$ molecular orbital, but in the tetrahedral geometry there is no nonbonding molecular orbital occupied, which gives a lower energy for the $\mathrm{T}_{\mathrm{d}}$ geometry than $\mathrm{D}_{4 \mathrm{~h}}$ geometry.

\section{BENT AND LINEAR THREE ATOM SPECIES WITH DOUBLE BONDS}

In addition to these simple cases above, it is intriguing, for example, why is the ozone molecule bent and $\mathrm{CO}_{2}$ linear? Table 8 shows several simple three atoms species and their electron valence 
Table 7. Applying the $\mathrm{D}_{4 \mathrm{~h}}$ symmetry operations to the atomic orbitals of the planar $\mathrm{CH}_{4}$ molecule

\begin{tabular}{ccrrrrrrrrrr}
\hline $\mathrm{D}_{4 \mathrm{~h}}$ & $\mathrm{E}$ & $2 \mathrm{C}_{4}$ & $\mathrm{C}_{2}$ & $2 \mathrm{C}_{2}^{\prime}$ & $2 \mathrm{C}_{2}^{\prime \prime}$ & $\mathrm{i}$ & $2 \mathrm{~S}_{4}$ & $\sigma_{\mathrm{h}}$ & $2 \sigma_{\mathrm{v}}$ & $2 \sigma_{\mathrm{d}}$ \\
\hline $\mathrm{A}_{1 \mathrm{~g}}$ & 1 & 1 & 1 & 1 & 1 & 1 & 1 & 1 & 1 & 1 \\
$\mathrm{~A}_{2 \mathrm{~g}}$ & 1 & 1 & 1 & -1 & -1 & 1 & 1 & 1 & -1 & -1 \\
$\mathrm{~B}_{1 \mathrm{~g}}$ & 1 & -1 & 1 & 1 & -1 & 1 & -1 & 1 & 1 & -1 \\
$\mathrm{~B}_{2 \mathrm{~g}}$ & 1 & -1 & 1 & -1 & 1 & 1 & -1 & 1 & -1 & 1 \\
$\mathrm{E}_{\mathrm{g}}$ & 2 & 0 & -2 & 0 & 0 & 2 & 0 & -2 & 0 & 0 \\
$\mathrm{~A}_{1 \mathrm{u}}$ & 1 & 1 & 1 & 1 & 1 & -1 & -1 & -1 & -1 & -1 & \\
$\mathrm{~A}_{2 \mathrm{u}}$ & 1 & 1 & 1 & -1 & -1 & -1 & -1 & -1 & 1 & 1 \\
$\mathrm{~B}_{1 \mathrm{u}}$ & 1 & -1 & 1 & 1 & -1 & -1 & 1 & -1 & -1 & 1 \\
$\mathrm{~B}_{2 \mathrm{u}}$ & 1 & -1 & 1 & -1 & 1 & -1 & 1 & -1 & 1 & -1 \\
$\mathrm{E}_{\mathrm{u}}$ & 2 & 0 & -2 & 0 & 0 & -2 & 0 & 2 & 0 & 0 \\
\hline$\left(\mathrm{s}^{\mathrm{H1}}, \mathrm{s}^{\mathrm{H}}, \mathrm{s}^{\mathrm{H}}, \mathrm{s}^{\mathrm{H}}\right)$ & 4 & 0 & 0 & 2 & 0 & 0 & 0 & 4 & 2 & $(x, y)$ \\
\hline
\end{tabular}

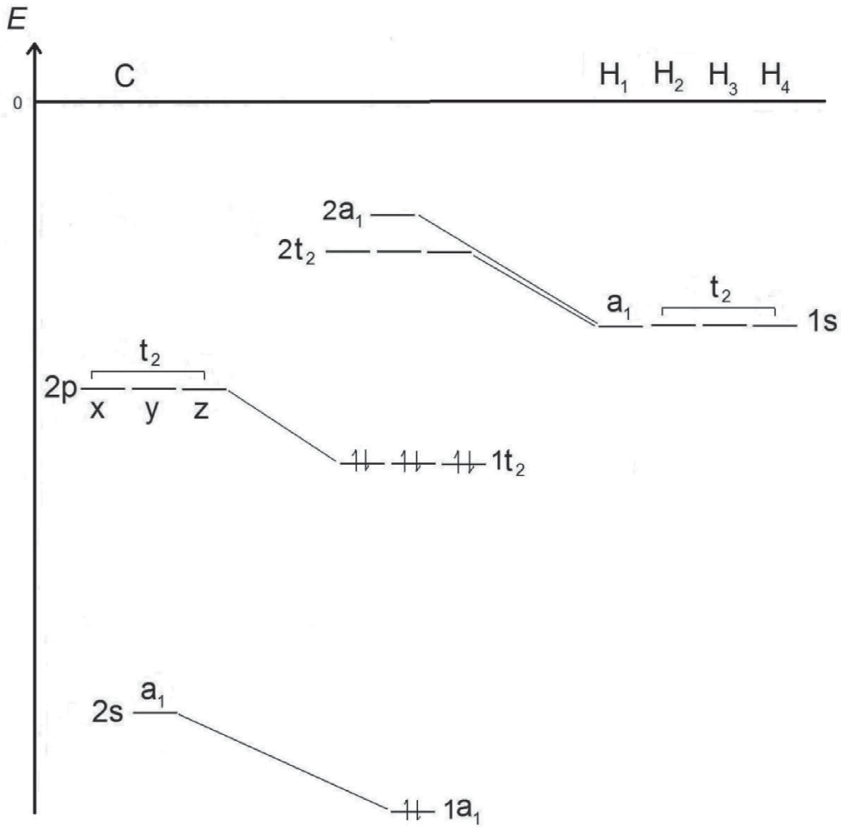

Figure 11. Qualitative molecular orbital energy-level diagram for $\mathrm{CH}_{4}$ in the tetrahedral geometry $\left(T_{d}\right)$

counting. As can be seen, only sixteen electron species can be linear $\left(D_{\infty \mathrm{h}}\right)$ as it was observed by other authors. ${ }^{9}$ To explain the geometries of the species shown in Table 8 using molecular orbital energy-level diagrams the situation now is more complex because instead of the terminal hydrogen atoms we have now oxygen or nitrogen atoms. It means that in addition to the s atomic orbitals, the terminal atoms have three $\mathrm{p}$ orbitals, which makes more difficult to produce simple molecular orbital energy-level diagrams. However, we can make a simple analysis considering only the $\pi$ frontier molecular, as it is shown in Figure 13 for the $\mathrm{CO}_{2}$ molecule.

Table 8. Trinuclear $\mathrm{AX}_{2}$ species and their electron valence counting and geometry

\begin{tabular}{ccc}
\hline $\begin{array}{c}\text { Number of valence } \\
\text { electrons }\end{array}$ & linear & bent \\
\hline 16 & $\mathrm{CO}_{2}, \mathrm{~N}_{3}^{-}$ & \\
17 & & $\mathrm{NO}_{2}^{-}$ \\
18 & & $\mathrm{O}_{3}, \mathrm{NO}_{2}^{-}, \mathrm{SO}_{2}$ \\
19 & $\mathrm{ClO}_{2}{ }^{-}$ \\
20 & & $\mathrm{ClO}_{2}^{-}$ \\
\hline
\end{tabular}

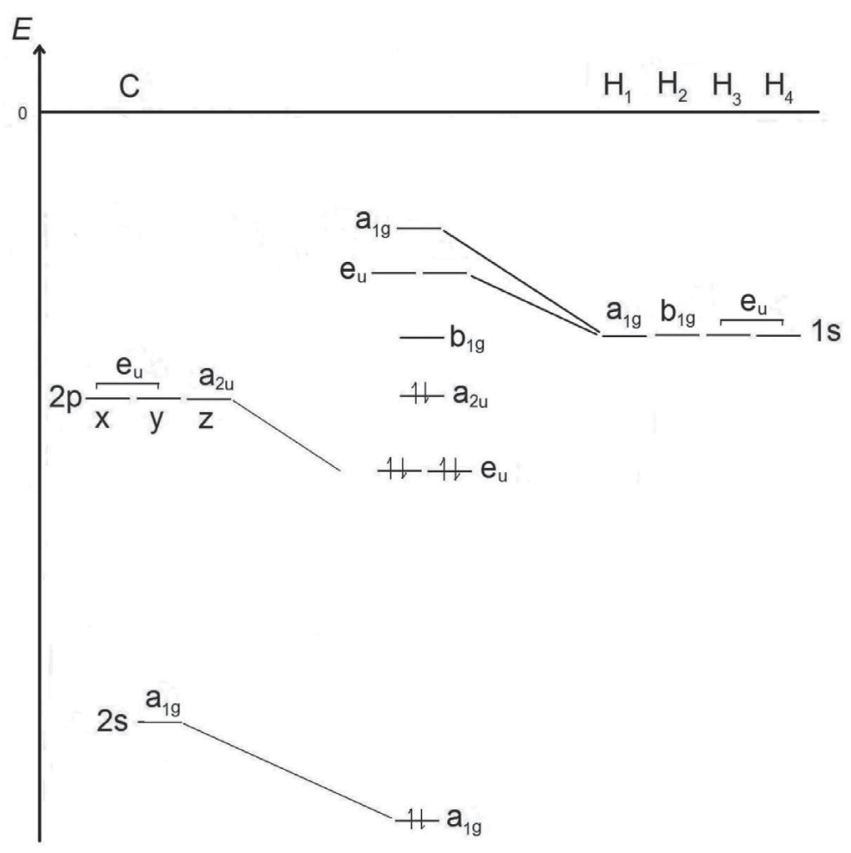

Figure 12. Qualitative molecular orbital energy-level diagram for $\mathrm{CH}_{4}$ in the planar geometry $\left(D_{4 h}\right)$

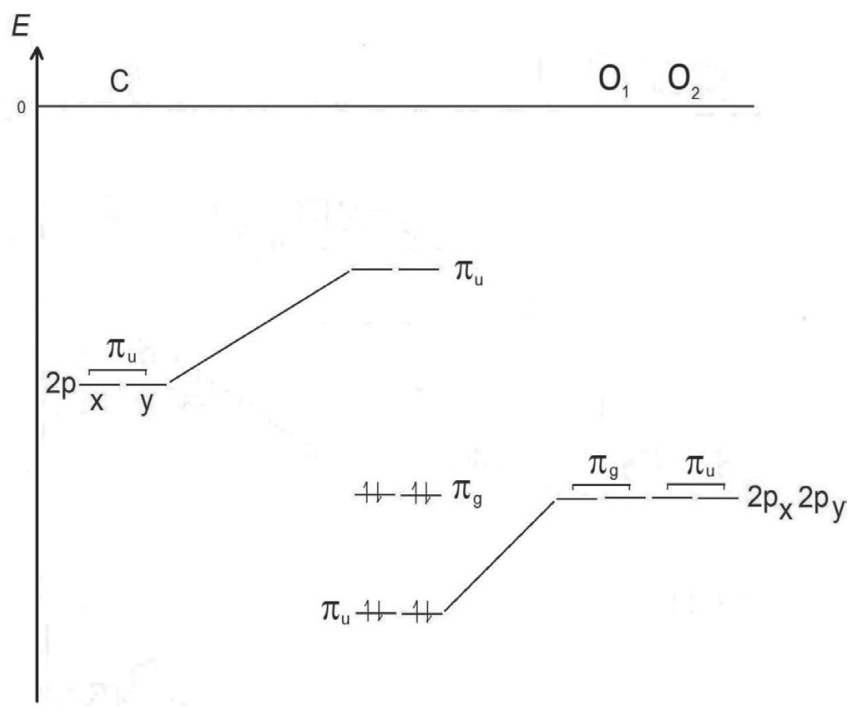

Figure 13. Simplified molecular orbital energy-level diagram for $\mathrm{CO}_{2}(16$ valence electrons) showing only the frontier $\pi$ orbitals 
As can be seen, the HOMO is a nonbonding $\pi_{\mathrm{g}}$ molecular orbital and the LUMO is an empty $\pi_{\mathrm{u}}$ antibonding molecular. For the species $\mathrm{N}_{3}{ }^{-}$the molecular orbital energy-level diagram is similar, with the $\pi_{\mathrm{u}}$ antibonding molecular orbital without electrons. However, for the species with more than 16 electrons in Table 8 , the $\pi_{\mathrm{u}}$ antibonding molecular orbital will be occupied and the linear geometry will have a higher energy than the bend geometry.

\section{CONCLUSION}

The use of qualitative molecular orbital energy-level diagrams build from simple principles of symmetry and group theory allows forecast the correct geometry between two possibilities for some simple molecules. The choice of the most stable geometry depends on the energy of all electrons in the molecule and their interactions. However, for the molecules $\mathrm{H}_{2} \mathrm{O}, \mathrm{NH}_{3}, \mathrm{CH}_{4}$, and some $\mathrm{AX}_{2}$ species ( $\mathrm{X}$ different of hydrogen), the decision between two geometric possibilities can be made only by counting the number of nonbonding electrons for each case.

This approach reinforces the importance of the knowledge of symmetry and molecular orbital principles and gives additional support to discussions of bonding and molecular geometry based in other principles as, for example, electron pair repulsion based in VSEPR theory or hybrid orbitals, which are more commonly teach in the beginning levels.

Molecules of the $\mathrm{AH}_{2}$ type, with a lower number of electrons than water, like $\mathrm{BeH}_{2}$, for example, cannot be discussed using the simple approach presented here. In this case and for many other species it is necessary use the more detailed Walsh diagrams, which consider the change in energy of the full set of valence shell molecular orbitals as the geometry is gradually changed between two possibilities. In addition, our approach does not allow a discussion of the angle in the case of $\mathrm{AH}_{2}$ bent molecules or $\mathrm{AH}_{3}$ pyramidal molecules. It is concerned only to the question between two extreme geometric possibilities like linear and bent $\left(\mathrm{AH}_{2}\right)$, planar or pyramidal $\left(\mathrm{AH}_{3}\right)$, etc. However, this simpler qualitative discussion has been able to improve the comprehension of the students in the symmetry concepts because this gives to them a strong answer to the question "why we need learn symmetry?"

\section{ACKNOWLEDGEMENT}

The authors thank the financial support by Conselho Nacional de Desenvolvimento Científico e Tecnológico-CNPq (Grants no. 306.050/2016-1 and 304.423/2014-9).

\section{REFERENCES}

1. Brady, J. E.; Russell, J. W.; Holum, J. A.; Chemistry: The Study of Matter and Its Changes, $3^{\text {rd }}$ ed., John Wiley \& Sons: New York, 2000.

2. Kotz, J. C.; Treichel, P. Jr.; Chemistry and Chemical Reactivity, $9^{\text {th }}$ ed., CENGAGE Learning: Stamford, 2015.

3. Brown, T. E.; LeMay, H. E., Jr.; Bursten, B. E.; Murphy, C.; Woodward, P.; Stoltzfus, M. E.; Chemistry: The Central Science, $13^{\text {th }}$ ed., Pearson Education Ltd.: Harlow, 2015.

4. Weller, M.; Overton, T.; Rourke, J.; Armstrong, F.; Inorganic Chemistry, $6^{\text {th }}$ ed., Oxford University Press: Oxford, 2014.

5. Miessler, G. L.; Fischer, P. J.; Tarr, D. A.; Inorganic Chemistry, $5^{\text {th }}$ ed., Pearson Education Ltd.: Harlow, 2013.

6. Housecroft, C.; Sharpe, A. G.; Inorganic Chemistry, $4^{\text {th }}$ ed., Pearson Education Ltd.: Harlow, 2012.

7. Bernath, P. F.; Spectra of Atoms and Molecules, Oxford University Press: Oxford, 1995.

8. Walsh, A. D.; J. Chem. Soc. 1953, 2260.

9. Walsh, A. D.; J. Chem. Soc. 1953, 2266.

10. Walsh, A. D.; J. Chem. Soc. 1953, 2288.

11. Walsh, A. D.; J. Chem. Soc. 1953, 2296.

12. Walsh, A. D.; J. Chem. Soc. 1953, 2301.

13. Walsh, A. D.; J. Chem. Soc. 1953, 2306.

14. Walsh, A. D.; J. Chem. Soc. 1953, 2321.

15. Mulliken, R. S.; J. Am. Chem. Soc. 1955, 77, 887.

16. Baird, N. C.; J. Chem. Educ. 1978, 55, 412.

17. Miller, C. S.; Ellison, M.; J. Chem. Educ. 2015, 92, 1040.

18. Orchin, M. M.; Jaffé, H. H.; J. Chem. Educ. 1970, 47, 372.

19. Harris, D. C.; Bertolucci, M. D.; Symmetry and Spectroscopy, Oxford University Press: Oxford, 1978.

20. Cotton, F.A.; Chemical Applications of Group Theory, $3^{\text {rd }}$. ed., John Wiley \& Sons: New York, 1990.

21. Carter, R; L.; Molecular Symmetry and Group Theory, John Wiley \& Sons: New York, 1998.

22. Kettle, S. F. A.; Symmetry and Structure - Readable Group Theory for Chemists, $3^{\text {rd }}$. ed.; John Wiley \& Sons: New York, 2007.

23. Laing, M.; J. Chem. Educ. 1987, 64, 124. 